\title{
A mechanism solution for predicting the collapse loads of slender plate girders when subjected to in-plane patch loading
}

\author{
T. M. ROBERTS \& K. C. ROCKEY
}

Mr A. C. G. Hayward, Fairfield-Mabey Ltd

The Paper gives a useful solution for the local strength of girders where stiffeners are not present at points of concentrated load. Examples are rolling loads and where bearings may not at all times be located directly beneath bearing stiffeners, as when thermal movement occurs. Double stiffeners can be used to encompass such movements, but may not always be justified. Also, when girders are supported during construction at points remote from the permanent stiffeners, adequate spreaders may be needed.

46. Are other failure mechanisms possible where a bearing is close to a bearing stiffener, and free to rotate? Fig. 15 shows the Authors' mechanism and a possible alternative mechanism close to a stiffener. Do alternative mechanisms require investigation?

47. Figure 16 shows direct bearing failure loads to reference 24 , i.e. web bearing over length given by $30^{\circ}$ distribution through flange as clause $27 \mathrm{e}$, BS $449^{21}$ or clause 2.6, Part 4, BS $153 .{ }^{25}$ For small values of length of applied patch load $c$, lower capacities than the Authors' solution are indicated. Perhaps this means that the $30^{\circ}$ usually assumed distribution angle is over-conservative. What were the web to flange connection details used in the Authors' tests? The mechanism implies a full strength connection, and that the patch load constrains the flange against twisting in its cross-section. Was this so in the tests, or must the flange possess sufficient torsional rigidity? Use of bearings (or loads) free to rotate in the cross-section of the girder might not permit the web to develop a plastic hinge at the web to flange connection if the flange were insufficiently rigid in torsion.

\section{Dr Roberts and Professor Rockey}

The alternative mechanism suggested by $\mathrm{Mr}$ Hayward is a possible mechanism when a bearing is close to a bearing stiffener and is free to rotate. However, it should be emphasized that upper and lower bound solutions are only valid for situations where, at collapse, only plastic deformations occur. This is not strictly

Paper published: Proc. Instn Civ. Engrs, Part 2, 1979, 67, Mar., 155-175. 

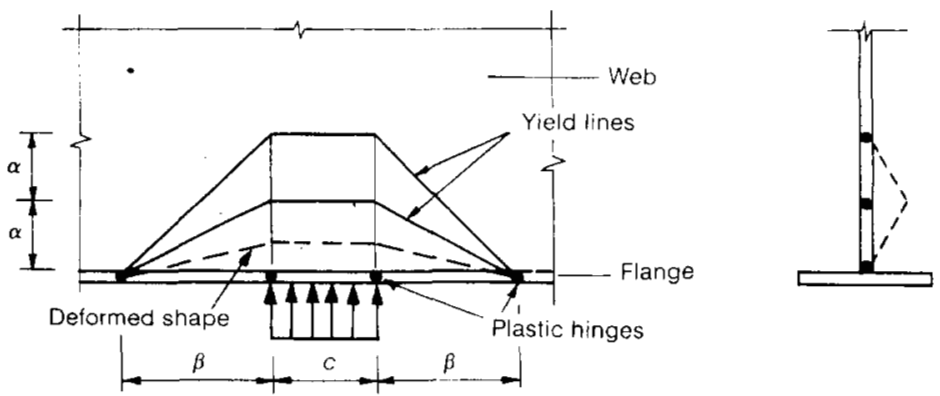

Authors' mechanism
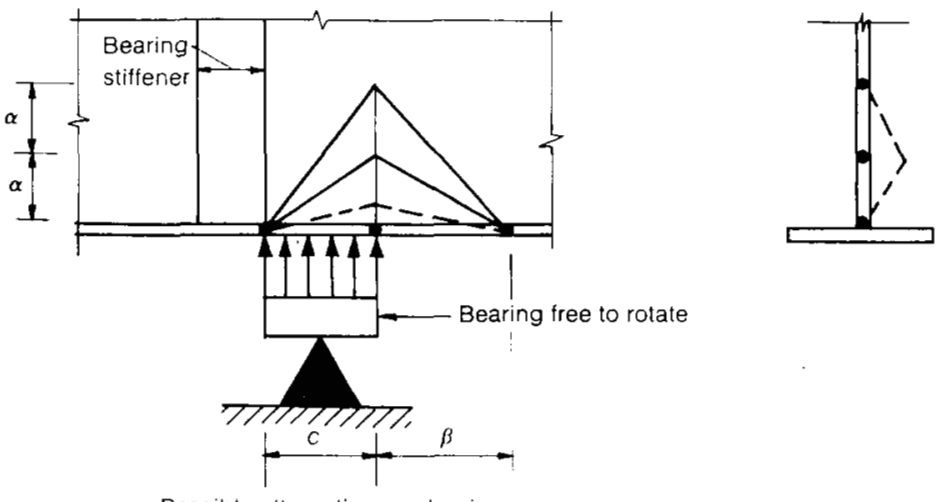

Fig. 15

true for geometrically non-linear problems and, irrespective of the empirical choice for $\alpha$, the present theory can only be fully justified by comparison with experimental results.

49. Experimental evidence suggests that failure loads given by a $30^{\circ}$ distribution through the flange tend to be conservative for stocky girders but considerably greater than actual failure loads for very slender girders, where instability effects predominate. At present we are unable to give any precise information regarding limiting slenderness ratios of webs, but this problem is currently being investigated.

50. For all the test girders, the flange to web connections were made with fillet welds. Due to residual stresses, the plastic moment in the web at the flange junction may be considerably reduced. This also requires further investigation.

51. For all girders tested to date, rotation of the flange was prevented by the loading arrangement. Preliminary tests indicate that it is likely that collapse loads will be affected by flange rotation and tendency to lateral instability.

52. The alternative mechanism suggested is a possible mechanism where a bearing is close to a bearing stiffener and is free to rotate. The modification to the existing theory is as follows. 


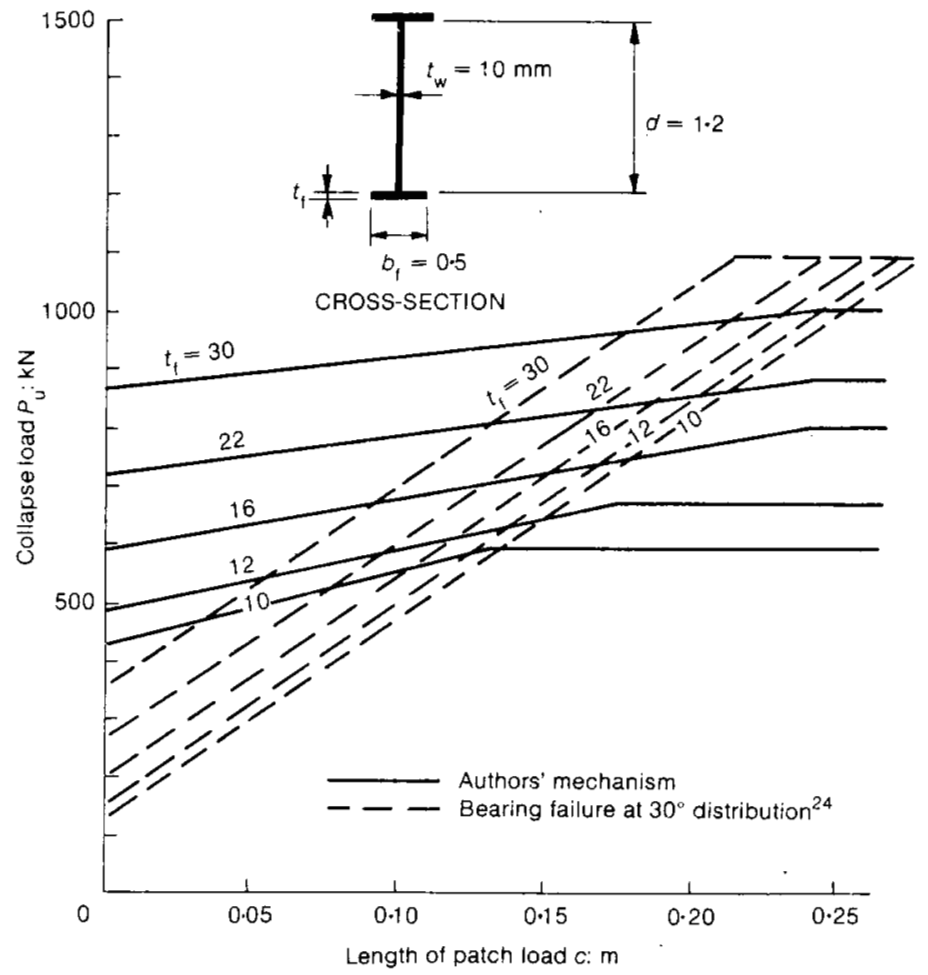

Fig. 16. Typical plate girder collapse loads

53. The work done by the external force $P_{\mathrm{u}}$ is now only half that for the original mechanism and equation (1) should be replaced by

$$
\frac{P_{u}}{2}=\frac{2 M_{\mathrm{f}}}{\beta}+\frac{2 M_{\mathrm{f}}}{c}+(\beta+c-\eta) \frac{2 M_{\mathrm{w}}}{\alpha \cos \theta}
$$

54. Equations (2)-(5a) remain the same but the equation for calculating $\eta$ becomes

Hence

$$
4(\beta+c-\eta) M_{w} / \alpha \cos \theta=\sigma_{w} t_{w} \eta
$$

$$
\eta=\frac{4(\beta+c) M_{w}}{\left[\left(4 M_{w} / \cos \theta\right)+\sigma_{w} t_{w}\right] \alpha \cos \theta}
$$

\section{References}

24. Department of Transport. Technical memorandum (bridges). Department of Transport, London, 1976, BE 3/76.

25. British Standards Instrutution. Steel girder bridges. Design and construction. British Standards Institution, London, 1972, BS 153, Part 4. 